\title{
Parenting and community engagement factors as predictors of religiosity among muslim adolescents from Malaysia.
}

\begin{abstract}
Despite the plethora of research on correlates of adolescent religiosity, few studies have examined the contribution of social context to religiosity among non-Western Muslim samples using multidimensional religiosity measures. To address this gap, the current study investigated the influence of community engagement and parenting factors on religiosity among 596 Malaysian Muslim secondary school students $(M$ age $=16.10, S D=.29)$. After controlling for gender, family structure, family income, and social desirability, the results showed that parental monitoring, mosque involvement, and school engagement significantly predicted religious worldview, whereas parental religious socialization, parental monitoring, mosque involvement, school engagement, and youth organization involvement accounted for a significant amount of the variance in religious personality. Implications for further research on socialization influences on religious development among adolescents are discussed.
\end{abstract}

Keyword: Parenting; Community engagement; Religiosity; Muslim adolescents; Malaysia. 